\title{
What broke me: A personal look at ED crowding and moral distress
}

\section{By Laura MacKinnon, RN, BSN, ENC(c), CEN, CPEN}

$\mathrm{I}$ sat in front of my computer on February 28 this year (2018) and started to write what I, ultimately, believed would be my resignation letter. Not just my resignation from my current job, by my resignation from nursing, in general. I had yet to complete my College of Registered Nurses of British Columbia (CRNBC) licence renewal and after my shift the day before, I was pretty sure I wasn't going back. I sat down with tears in my eyes and wrote what I felt, and I felt broken.

The events from my shift the day before still loomed over me; I hadn't slept well, I was emotional and hurting and the thought of going back to work was overwhelming. I didn't really want to quit, I love being a nurse, and I love my job in the ED, but I couldn't imagine having another experience similar to what happened on my last shift. In my mind, the events of the day before were worse than anything that I had ever experienced in my previous 11 years of nursing experience.

The thing is, the events of my previous shift weren't much different from any other day in our ED. We were busy, in the peak of another never-ending flu season and still seemingly recovering from the disaster that is Christmas time. Our department was seeing above average daily visits, baseline staffing levels were only being met $50 \%$ of the time, length of stays for admitted patients were gradually increasing with more patients being cared for in the hallways. The hospital was consistently over-capacity, with many days over $110 \%$. With nowhere for the patients to go, they stayed in the ED. They stayed in ED for hours, sometimes 24 or more. At times, they stayed in the ED because they weren't deemed "hallway appropriate" on the medical/surgical floor they were intended to go to, yet here they were, in the hallway of the ED: no curtains, no privacy, no confidentiality, no dignity and nowhere to go. It was ultimately a simple interaction with one of these hallway patients who only needed to use the bathroom and couldn't that caused me to reconsider the path I had chosen.

\section{Negative effects of ED crowding}

Hallway nursing isn't new in this country, or emergency nursing in general, but it is the current reality even though the negative effects of ED crowding on patients are detailed and compelling. ED crowding negatively affects both admitted patients and the ED itself by "consum[ing] substantial amounts of resources and labor... prevent[ing] staff from treating the next patient, or bringing in a new patient from the waiting room" (Bernstein et al. 2006, p. 3). A 30\% relative increase in the mortality rates of patients admitted through the ED is shown when ED crowding is present and hospital occupancy was greater than 90\% (Spivulis, Da Silva, Jacobs, Frazer \& Jelinek, 2006). The increased mortality rates were "independent of patient age, season, diagnosis or urgency” (Spivulis, Da Silva, Jacobs, Frazer \& Jelinek, 2006, p. 211).
Crowding also results in delays in the administration of antibiotics, pain medication, as well as thrombolytic and percutaneous therapy in patients with AMI (Johnson \& Winkleman, 2011). Along with delays in treatment, ED patients who are not admitted to hospital can also expect to spend longer in the ED when crowding occurs. White el al. (2013) report that during peak times of 1100-2300 hours, patients can expect to spend up to 23\% longer in the ED before discharge. Derlet and Richards (2000) believe that public safety is at risk due to ED crowding. Crowding results in patients not getting proper assessments or reassessments by nurses and physicians, which lead to delays in diagnosis and treatment (Derlet \& Richards). As ED crowding worsens and care areas fill up, patients are often treated in unconventional areas such as storage rooms and hallways (Stoklosa et al., 2018). When patients are in the hall receiving care and treatment, $78 \%$ of physicians reported deviating from their standard history taking while $90 \%$ altered their physical exam (Stoklosa et al.).

Patient satisfaction also suffers with overcrowding: patients have a higher rate of left without being seen (LWBS) and are more likely to wait longer and therefore return sicker the next time they require care (Pines et al. 2008). Not only do patient satisfaction scores drop with ED crowding, nurse satisfaction with "quality-related outcomes from nursing care" is compromised as is quality care (Johnson \& Winkelman, 2011, p. 51).

Quality care underlies nursing professional standard and regardless of which province a nurse works in, they must practise to a set of standards set out by their college or regulatory body. According to the CRNBC, professional standards "provide an overall framework for the practice of nursing in BC. They set out minimum levels of performance that nurses are required to achieve" (2018, p.3). Moreover, as ED crowding worsens, patients are cared for in inappropriate areas and medications and treatments are delayed, nurses may be forced to care for patients in a manner well below the minimum standards that are demanded by their respective colleges. Patients are put into the hall because there is nowhere else to go. The hospital is full and yet sick and dying people are still coming into the ED. When patients are in the hall we can no longer meet our standards. Patients are stripped of dignity, confidentiality and respect. We take away safety measures and instead impose a new vulnerability onto the already compromised patient. Our ethics are compromised along with our standard of care.

\section{Moral distress in the ED}

Moral distress is defined by Jameton (1984) as "when one knows the right thing to do, but institutional constraints make it nearly impossible to pursue the right course of action" (p. 6). Wolf et al. (2016) suggest that moral distress "arises when a nurse's internal values and perceived responsibilities are incompatible with the predominant views of the work environment 


\section{I am broken}

On February 27, 2018, I worked what I would consider to be the worst shift ever in the Emergency Room. I am a nurse and I love my job. I think I'm a pretty good nurse, certainly not the best, but rest assured, if you are my patient, I've got your back. I take pride in my credentials and abilities. I have tried to better myself by taking as many courses as I can. I try to stay up to date on things, I try to meet the standards that I am sure I have set way too high. I have been an $\mathrm{RN}$ for more than 11 years, and an LPN for two years before that and never have I witnessed anything as heartbreaking as I did during this particular shift. To give that perspective, I have seen countless people die, of natural causes, old age, heart attacks and strokes. I have seen trauma. I have seen unspeakable things. Things most people cringe to hear about. I have asked for the organs, tissues and eyes of the dying and recently deceased before the bodies are even cold. I have watched parents collapse, as they learn that we will be stopping CPR and resuscitation efforts of their child. I have placed the bodies of dead infants back into their mothers' arms for the last time. I have handed stillborn babies to their mothers for the first and only time. I have seen bodies ripped apart, missing limbs, crushed and broken. I have seen abuse in all forms. I have carried the body of an infant in my arms to the morgue after she had her head crushed by a caregiver who threw her into a wall. I have seen what drugs and alcohol do, not just to the person who did it one time, but also to the person who is dying from a lifetime of addiction. I have been part of many conversations where patients learn they will never be going home. I have explained diseases and disease processes to patients, so they understand that their time on this earth is now limited. I have held the hands of those same patients and their families while the priest blesses them with Last Rights. I have been assaulted, by patients and their families, verbally and physically so many times I have lost count. I have found concealed weapons on patients who had intent to harm anyone in their way in order to escape police custody. I have done these things day after day, year after year, because it's been my job. I am a nurse and this is what I do, it is who I am. I have managed to separate the emotional baggage of these things from my life. They are horrible and unspeakable, but they happen... and when they do, I will be there with as much compassion and knowledge and experience as I can muster. Until last night... now I am unsure.

Our hospital is in crisis. I cannot see how anyone can dispute this. We run at or above capacity most days. With the rising population and lack of primary care for so many, this will not end anytime soon. This causes a backlog of patients waiting in the ER. It causes patients to receive care in hallways and other inappropriate care areas throughout our hospital. This is simply undignified. Lack of safety aside, imagine feeling sick and miserable lying on a hospital stretcher, in a hospital gown, in the middle of the hallway. You are on display for everyone. Everything you do is seen and heard. Every question that is asked of you is heard. Every time you vomit, everyone sees it. Every time you go to the bathroom, every one will know. There is rarely even the semblance of privacy. There are no half curtains or rolling screens in the $\mathrm{ER}$, there are only open halls.

Last night, as is typical of most nights lately in the ER, the hallway was lined with patients. As I walked up the hall, I passed a man who looked like he was struggling. His IV was stretched to the limit, he was half out of the bed, he appeared somewhat agitated and confused, he had a urinal bottle in one hand and a family member on each side of him. I quickly jumped in and rescued and secured his IV site and then asked about his obvious need to use the bathroom. His family were sure that given his current state he would not be able to walk the 20 feet down the hall to the bathroom, but he was desperate to go. The patient stood in the hall next to his stretcher while his family created a curtain around him with a flannel sheet. The patient then attempted to use the urinal. I am sure that due to his level of unwellness, coupled with the awkwardness of the makeshift curtain, he was unable to use the urinal successfully. He urinated all over the floor, himself and my shoes. I lied and told him he was doing a great job, and looked to his daughter to see tears overflowing in her eyes. All she could say was "this is so wrong, no one should have to do this". I can only imagine how humiliated and embarrassed she felt for herself and her father. I cannot imagine how angry I would have been if that had been my father. All I could think about was that this level of care is substandard. This is the level of care provided in third world countries. This should not be accepted in Canada, Island Health, the Victoria General Hospital or the ER. Of all the horrible things I have witnessed, this is it, this is what has broken me.

I was reviewing our Standards of Practice when doing my license renewal.

1-4. Takes action to promote the provision of safe, appropriate and ethical care to clients.

4-2. Provides care in a manner that preserves and protects client dignity.

Every time we put a patient in the hallway we fail on these standards. The patient is stripped of their dignity, confidentiality, safety and they are left exposed and vulnerable. Not one single staff member would be satisfied to have a member of their own family treated in this manner. Why have we become so complacent as to continually accept it when it is someone else's family? I challenge you to explain why this is allowed to continue on a daily basis.

I do not know where to go from here. I do know that there needs to be a change. Soon. No more patients deserve to be treated like this. No more patients should be treated like we are in the third world. I have spent the last 24 hours questioning if I want to go back to work. I certainly don't want to, but I feel like I need to. I need to be part of the change, part of the solution. I don't have the answers, but I want to find them.

Until we all acknowledge the problem, report the problem and demand a change, there will be no change. This will become the status quo and complacency will rule. To my colleagues, I ask that you push back and report the unsafe patient care. Report that you are not able to meet your standards. Force the change. To the management, I ask that you listen and act to support your staff and the patients. Would anyone of you really be happy to be treated this way?

\section{Laura MacKinnon, RN, BSN, ENC(c), CEN, CPEN \\ Staff Nurse, Victoria General Hospital Emergency}


and culture" (p. 39). Episodes of moral distress were reported by ED nurses when they felt they were providing "futile care" or if care was perceived to be provided by a less than competent provider. (Fernandez-Parsons, Rodriguez \& Goyal, 2013).

A small study done by Kilcoyne and Dowling (2007) showed that nurses who were forced to pull admitted patients in the ED to hallways showed moral conflict and moral distress due to being unable to carry out their role, patients being vulnerable, lacking privacy, dignity and respect and being unable to meet basic human needs. ED overcrowding and hallway nursing is typically a gradual and adaptive modification to allow daily functioning in the ED and as such staff are able to adapt slowly to this change. The normalization of these conditions may be a factor in the levels of anxiety, stress, fear, frustration a poor sense of safety and security that providers view as barriers to the nursing role (Kilcoyne \& Dowling, 2007).

Lamiani, Borghi and Argentero (2017) looked at studies exploring moral distress and the work environment and found "moral distress to be associated with poor ethical climate" (p. 63 ). They further determined that organizational factors were consistently linked to causes of moral distress. Several of the studies reviewed by Lamiani, Borghi and Argentero reported that "as a consequence of moral distress, clinicians might experience anger, frustration, guilt... and intention to resign from a job” (p. 63).

While the feeling of powerlessness is common when discussing moral distress, Rodney (2017) suggests that this is because providers have "internalized constraints [and] they view themselves as "victims" of moral distress rather than as individuals with moral agency capable of responding positively to ethically challenging situations" ( $p$. S8). The term moral resilience has emerged in the literature and is seen as "the capacity of an individual to sustain or restore [her or his] integrity in response to moral complexity, confusion, distress, or setbacks" (Rushton, as cited in Rodney, p. S9). If nurses are able to develop moral resiliency they may feel less powerless and victim to the situations causing moral distress. Rodney states that "with proper support-including the opportunity for self-reflection and for true collaboration with other clinicians and with colleagues in management-nurses can create a climate that promotes safe, competent, and ethical care" (p. S9).

\section{Building resiliency}

Repeated events of moral distress may result in "moral residue". Moral residue is described as "that which each of us carries with us from those times in our lives when in the face of moral distress, we have seriously compromised ourselves or allowed ourselves to be compromised" (Webster \& Bayliss as cited in Wolf et al, 2016, p. 44). Epstein and Hamric (2009) describe moral residue as having a crescendo effect. Repeated, unaddressed episodes of moral distress over time cause moral residue essentially altering the threshold for new exposures to morally distressing events. After 10 years of working in the ED and experiencing these events, it took a relatively small event to evoke a massive and disproportionate response. No one died, there was no severe dismemberments or any lifelong harm. Despite that, I was affected more than any of the other things I have done in my career. I can only assume that is due to repeated events of moral distress that I now carry that with me, more so than I thought, in the form of moral residue.

When I sat to write out my resignation letter that day, I felt the frustration, guilt and powerlessness, but mostly I was angry. I angry that after 10 years seeing the lowest lows you can imagine working in an ED, that a hallway patient needing desperately to go to bathroom and unable to do so was the thing that made me want to quit. In my writing, I became angrier, more hurt and even worse, I felt let down by a system that I believed should have done better to prevent this. When I had finished my letter, I read it over and over. If I quit, I would never help another person, I would never get a chance to prevent this from happening again and I would be wasting an amazing gift. Instead of resigning, I finished my letter by challenging my organization to change. I challenged them to consider that they could do things better and finally, after long conversation with my much-more rational husband I decided that I would send my letter throughout the department I worked in and beyond to upper levels of administration. Then, with just an hour to spare, I completed my licence renewal. I would return to work, determined to do better, determined that change will happen.

My letter was surprisingly well received and I received a significant amount of positive feedback based on what I did and it shows me that I am not alone in my distress. Since sending it, I have been actively working on creating solutions and working toward change within the organization I work for. It is slow, but it's happening. It hurts me, but it is also healing. So, I did go back to work in the ED, I still love my job... most days. I still get excited to hear the sirens, to go to the trauma room, to get the IV into the three-day-old baby and pull life back from the brink of death. Speaking out in the way I did may have been dramatic to some, but for me it was my way of reclaiming moral agency and challenging institutional practices. But every time I walk up our hallway and see patients lying in our hallway, I feel the ache and I remember what broke me.

\section{Author's take-aways}

1. You are probably not alone if you experiencing moral distress, connect with those you work with about what you are experiencing and feeling.

2. Frontline staff and ED leaders need to work together, along with patient representatives, to improve the provision of care under challenging circumstances such as crowding.

3. ED nurses' proximity to patients, both physically and emotionally, leave us feeling our patients' distress.

4. Improving the quality of our workplace can improve the quality of care provided.

\section{About the author}

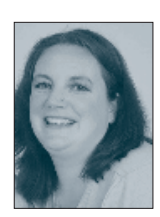

Laura MacKinnon, $R N, B S c N, E N C(c), C E N, C P E N$

Laura is an emergency nurse in Victoria BC. She has worked in EDs in four provinces and teaches TNCC and CTAS. She is a wife to the "much-more rational" Fraser, a fellow ED nurse and the mom of twin threeyear-old boys. Laura is currently enrolled the Masters

of Nursing program at Athabasca University. 
Bernstein, S.L., Boggs, R., Derlet, R., Handly, N., Hinfey, P. \& Kamens, D. (2006). Emergency department crowding: Past, present and future directions. American Academy of Emergency Medicine.

Bernstein, S.L., Aronsky, D., Duseja, R., Epstein, S., Handel, D., Hwang, U., ... Emergency Department Crowding Task Force. (2008). The effect of emergency department crowding on clinically oriented outcomes. Academic Emergency Medicine Journal, 16(1), 1-11.

College of Registered Nurses of British Columbia. (2018). Professional standards. Retrieved from https://www.crnbc.ca/Standards/ ProfessionalStandards/Pages/Default.aspx

Derlet, R.W., \& Richards, J.R. (2000). Overcrowding in the nations emergency departments: complex causes and disturbing effects. Annals of Emergency Medicine, 35(1), 63-68.

Epstein, E.G., \& Hamric, A.B. (2009). Moral distress, moral residue and the crescendo effect. Journal of Clinical Ethics, 20(4), 330-342.

Fernandez-Parsons, R., Rodriguez, L., \& Goyal, D. (2013). Moral distress in emergency nurses. Journal of Emergency Nursing, 39(6), 547-552.

Jameton, A. (1984). Nursing Practice: The Ethical Issue. Englewood Cliffs, NJ: Prentice Hall.

Johnson, K.D., \& Winkelman, C. (2011). The effect of emergency department crowding on patient outcomes: A literature review. Advanced Emergency Nursing Journal, 33(1), 39-54.

Kilcoyne, M., \& Dowling, M. (2007). Working in an overcrowded accident and emergency department: Nurses' narratives. The Australian Journal of Advanced Nursing, 25(2), 22-27.
Lamiani, G., Borghi, L., \& Argentero, P. (2017). When healthcare professionals cannot do the right thing: A systematic review of moral distress and its correlates. Journal of Health Psychology, 22(1), 51-67.

Pines, J.M., Iyer, S., Disbot, M., Hollander, J.E., Shofer, F.S., \& Datner, E.M. (2008). The effect of emergency department crowding on patient satisfaction for admitted patients. Journal of the Society for Academic Emergency Medicine, 15(9), 825-831.

Rodney, P.A. (2017). What we know about moral distress. American Journal of Nursing, 117(2), S7-S10.

Sprivulis, P.C., Da Silva, J., Jacobs, I.G., Frazer, A.R., \& Jelinek, G.A. (2006). The association between hospital overcrowding and mortality among patients admitted via Western Australia emergency departments. Medical Journal of Australia, 184(5), 208-212.

Stoklosa, H., Scannell, M., Ma, Z., Rosner, B., Hughes, A., \& Bohan, J.S. (2018). Do EP's change their clinical behaviour in the hallway or when a companion is present? A Cross-sectional survey. Emergency Medicine Journal, 35(7), 406-411.

White, B. A., Biddinger, P. D., Chang, Y., Grabowski, B., Carignan, S., \& Brown, D. F. (2013). Boarding inpatients in the emergency department increases discharged patient length of stay. The Journal of Emergency Medicine, 44(1), 230-235.

Wolf, L.A., Perhats, C., Delao, A.M., Moon, M.D., Clark, P.R. \& Zavotsky, K.E. (2016). "It's a burden you carry": Describing moral distress in emergency nursing. Journal of Emergency Nursing, $42(1), 37-46$. 